\title{
PENGARUH PERAN IBU DALAM PEMELIHARAAN KESEHATAN GIGI DAN MULUT TERHADAP KEJADIAN KARIES GIGI PADA SISWA KELAS I SD NEGERI JUBELAN 02 KECAMATAN SUMOWONO
}

\author{
Endah Aryati Eko Ningtyas1, Umi Salamah Apriliana², Erni Mardiati ${ }^{3}$
}

\begin{abstract}
The role of mother in the maintenance of oral health includes the removal of plaque and debris on the teeth that can be done every day with a toothbrush, supervise child's diet, eliminating bad habits and check their child's teeth or facilities to health facilities is a factor that plays a role in preventing caries teeth in children. Dental caries is one form of tooth decay is most often experienced by children of school age. The incidence of dental caries in primary school students in the District of Sumowono Jubelan 02 is the average def-t 8.1 and DMF-T 1.6. The purpose of this study was to determine the role of the mother in the maintenance of oral health on the incidence of dental caries in first grade primary school students Jubelan 02 District of Sumowono 2014. This research is a descriptive cross sectional design research.

The population in this study were for 24 student, all students in first class of Primary School of Jubelan 02 Sumowono, Semarang. Analisis is doing descriptively by cross tabulation. Measures used was a questionnaire. The results showed that all the mother's role in the maintenance of oral health is Most of the categories, but the incidence of caries included in the high category in the amount of $75 \%$. The results showed that no influence of the mother's role in the maintenance of oral health on the incidence of caries incidence in children of primary school age.
\end{abstract}

Key words : Role Mommy, Maintenance Dental and Oral Health, Dental Caries Genesis

1,3) Dosen Jurusan Keperawatan Gigi Poltekkes Kemenkes Semarang

2) Mahasiswa Jurusan Keperawatan Gigi Poltekes Semarang

\section{PENDAHULUAN}

Masalah kesehatan gigi dan mulut anak, khususnya karies gigi masih memerlukan perhatian yang cukup besar. Gultom (2009) menyatakan bahwa pencegahan karies merupakan penekanan program pemeliharaan kesehatan gigi pada anak uasia sekolah. Machfoedz (2008) menyatakan pula bahwa dalam hal menjaga kesehatan gigi dan mulut, anak usia sekolah masih tergantung pada orang tua khususnya ibu.Para ibu harus mengetahui bahwa pemeliharaan kesehatan gigi pada anak merupakan tanggung jawab mereka.Masalah kesehatan gigi dan mulut anak, khususnya karies gigi masih memerlukan perhatian yang cukup besar. Organisasi Kesehatan Dunia (WHO) pada tahun 2003 menyatakan angka karies gigi masih sebesar 60-90\%. Hasil Riset Kesehatan Dasar 2007, menunjukkan bahwa prevalensi penyakit gigi dan mulut pada anak usia 5-9 tahun mencapai $27,3 \%$. Peranan ibu sangat diperlukan dalam membentuk perilaku anak di dalam membimbing memberikan pengertian, mengingatkan dan menyediakan fasilitas kepada anak agar anak dapat memelihara kebersihan gigi dan mulutnya. Peran ibu dalam menjaga kesehatan rongga mulut meliputi pembersihan plak dan debris pada gigi yang dapat dilakukan setiap hari dengan menggunakan sikat gigi (Machfoedz, 2008). 
Anak usia sekolah, masih sangat bergantung pada orang tua dalam hal menjaga kesehatan gigi dan mulutnya. Pada saat kemampuan motorik seorang anak belum maksimal, maka peran orang tua sangat diperlukan untuk tetap membantu memelihara kebersiha rongga mulutnya.Peran seorang ibu untuk mendampingi dan menyikat gigi harus tetap dilakukan sampai anak dapat menerima tanggung jawab secara penuh (Wong, 2009).

Berdasarkan laporan Puskesmas Sumowono diperoleh data kesehatan gigi dan mulut di SD Negeri Jubelan 02 masih memerlukan perawatan sebesar 50,4\% (Laporan Puskesmas Sumowono, 2013). Sedangkan studi pendahuluan yang dilakukan di SD Negeri Jubelan 02 pada bulan April 2014 terhadap seluruh siswa kelas I yang berjumlah 24 siswa didapatkan rata-rata def-t 8,1 dan rata-rata DMF-T 1,6. Diketahui bahwa orang tua siswa SD Negeri Jubelan 02 berusia kisaran 26 - 40 tahun. Kebanyakan dari ibu siswa yang bekerja sebagai buruh pabrik dibandingkan dengan ibu rumah tangga biasa. Ibu biasanya berangkat kerja pagi hari dan pulang kerja menjelang sore, sehingga waktu untuk bertemu dengan keluarga terutama anak sangat sedikit.

Tujuan penelitian adalah mengetahui Bagaimanakah Pengaruh Peran Ibu Dalam Pemeliharaan Kesehatan Gigi dan Mulut Terhadap Kejadian Karies Gigi Pada Siswa Kelas I SD Negeri Jubelan 02 Kecamatan Sumowono Tahun 2014.

\section{METODE PENELITIAN}

Jenis penelitian yang dilakukan adalah penelitian survey yang bersifat deskriptif kuantitatif yaitu metode yang dilakukan dengan tujuan untuk mendapatkan gambaran atau deskriptif tentang suatu keadaan secara obyektif. Dengan pengambilan data menggunakan metode cross sectional yaitu penelitian sesaat dimana pengambilan data variabel pengaruh dan terpengaruh di lakukanya pada waktu yang bersamaan (Notoadmojo, 2012). Populasi dalam penelitian ini adalah siswa kelas I SD Negeri Jubelan 02 Kecamatan Sumowo dan sampel dalam penelitian ini adalah siswa kelas 1 SD Negeri Jubelan 02 berjumlah 24 anak. Langkah-langkah pelaksanaan penelitian adalah : (1) Melakukan penelitian pada anak yaitu melakukan pemeriksaan karies kepada siswa yang kooperatif berumur 6-7 tahun, mencatat hasil pemeriksaan ke lembar pemeriksaan dengan memberikan kode pada lembar pemeriksaan sesuai dengan nomor absen siswa, (2) Melakukan penelitian pada ibu siswa yaitu membagi kuesioner kepada ibu siswa, dan memberikan kode pada lembar kuesioner sesuai dengan nomor absen siswa, memberikan pengarahan atau instruksi tentang cara pengisian kuesioner, serta maksud dari pembagian kuesioner.

\section{HASIL DAN PEMBAHASAN}

Tabel 1. Distribusi Frekuensi Kategori Peran Ibu Dalam Pemeliharaan Kesehatan Gigi dan Mulut Anak

\begin{tabular}{|c|c|c|c|}
\hline \multirow{2}{*}{ No } & Kriteria & \multicolumn{2}{|c|}{$\begin{array}{r}\text { Peran Ibu memelihara } \\
\text { kesehatan gigi dan } \\
\text { mulut anak }\end{array}$} \\
\cline { 3 - 4 } & & Jumlah & $(\%)$ \\
\hline 1 & Tinggi & 6 & 25 \\
\hline 2 & Sedang & 14 & 58,33 \\
\hline 3 & Rendah & 4 & 16,67 \\
\hline & jumlah & 24 & 100 \\
\hline
\end{tabular}

Berdasarkan Tabel 1 diatas dapat dilihat bahwa peran ibu dalam pemeliharaan kesehatan gigi dan mulut yang paling dominan adalah pada kriteria sedang yaitu 14 responden (58,33\%), dan peran ibu dengan kriteria rendah sebanyak 4 responden $(16,67 \%)$

Tabel 2. Distribusi frekuensi kejadian karies gigi pada siswa kelas 1 SD Negeri Jubelan 02

Kecamatan Sumowono

\begin{tabular}{|c|c|c|c|}
\hline \multirow{2}{*}{ No } & \multirow{2}{*}{ Kriteria } & \multicolumn{2}{|c|}{$\begin{array}{c}\text { Peran Ibu memelihara } \\
\text { kesehatan gigi dan mulut } \\
\text { anak }\end{array}$} \\
\cline { 3 - 4 } & & Jumlah & $\%$ \\
\hline 1 & Tinggi & 6 & 25 \\
\hline 2 & Rendah & 18 & 75 \\
\hline & jumlah & 24 & 100 \\
\hline
\end{tabular}


Berdasarkan Tabel 2 diatas dapat dilihat bahwa kejadian karies gigi pada siswa kelas 1 adalah kriteria rendah.

Tabel 3. Tabulasi Silang Peran Ibu Dalam Pemeliharaan Kesehatan Gigi dan Mulut Terhadap Kejadian Karies Gigi

\begin{tabular}{|c|c|c|c|c|c|c|}
\hline \multirow{2}{*}{ Peran Ibu } & \multicolumn{6}{|c|}{ Karies Gigi } \\
\cline { 2 - 7 } & \multicolumn{2}{|c|}{ Rendah } & \multicolumn{2}{|c|}{ Tinggi } & \multicolumn{2}{c|}{ Total } \\
\cline { 2 - 7 } & $\mathrm{n}$ & $\%$ & $\mathrm{n}$ & $\%$ & $\mathrm{n}$ & $\%$ \\
\hline Tinggi & 2 & 8,33 & 4 & 16,67 & 6 & 25 \\
\hline Sedang & 1 & 4.17 & 13 & 54,17 & 14 & 58,33 \\
\hline Rendah & 3 & 12,5 & 1 & 4,17 & 4 & 16,67 \\
\hline Jumlah & 6 & 25 & 18 & 75 & 24 & 100 \\
\hline
\end{tabular}

Berdasarkan Tabel 3 diatas dapat dilihat bahwa pada peran ibu dengan kriteria sedang $(4,17 \%)$ ternyata kategori kejadian karies anaknya juga tinggi $(4,17 \%)$ tetapi pada peran ibu yang kriteria rendah $(12,5 \%)$ kategori kejadian karies anaknya paling rendah $(4,17 \%)$

Hasil penelitian menunjukkan bahwa kejadian karies gigi anak sebagian besar terdapat pada kategori tinggi sebesar 54,17 $\%$ dengan ibu yang berperan sedang sebesar $58,33 \%$. Hal ini berarti bahwa sebagian responden cukup berperan dalam pemeliharaan kesehatan gigi dan mulut anaknya, beberapa hal yang telah dilakukan seperti mengingatkan anak untuk menyikat gigi dua kali sehari, rutin mengkonsumsi buah dan sayur, dan menggunakan pasta gigi yang mengandung flour. Hal ini cukup baik karena menjaga kesehatan gigi dan mulut dengan menyikat gigi dan menjaga pola makan dapat mengurangi resiko terjadinya karies gigi (Rahayu, 2010). Menurut Machfoedz (2008) apabila dalam satu keluarga, gigi anak-anaknya sehat, tentu karena orang tua khususnya ibu dapat memperhatikan kesehatan gigi anakanaknya. Dalam upaya pembinaan kesehatan, aspek kesehatan gigi tidak dapat diabaikan, terutama dalam periode pertumbuhan anak. Tingkat kesehatan gigi dan mulut mempengaruhi pertumbuhan anak yang sempurna dan generasi yang sehat (Rahayu, 2010).
Penanganan masalah gigi anak dipengaruhi oleh ilmu pengetahuan, kesadaran, dan kebiasaan ibu dalam menjaga kesehatan gigi dan mulut. Karakteristik ibu siswa berdasarkan tingkat pendidikan bahwa sebagian besar responden adalah berpendidikan dasar SD sebesar 54,17\%. Menurut Rahayu (2010) pengetahuan atau kebiasaan yang dimiliki orang tua antara lain bersangkutan dengan cara membersihkan gigi dan mulut, mengatur pola makan, dan memeriksakan gigi secara rutin.

Pendidikan merupakan hal yang sangat penting dalam mempengaruhi pikiran seseorang. Melalui proses pendidikan yang melibatkan serangkaian aktivitas, maka seorang individu akan memperoleh pengetahuan, pemahaman, keahlian dan wawasan yang lebih tinggi (Rizka, 2010). Kemungkinan responden tidak pernah mendapatkan informasi atau sosialisasi tentang kesehatan gigi dan mulut sehingga kurang paham terhadap akibat penyakit gigi dan mulut. Peran dalam pemeliharaan kesehatan gigi dan mulut dilakukan sebatas apa yang diketahui ibu, sehingga banyak responden yang melakukan upaya dalam pemeliharaan kesehatan gigi dan mulut tetapi dengan cara yang kurang benar.

Dari Tabel 3 didapatkan hasil bahwa peran ibu dalam memelihara kesehatan gigi dan mulut pada siswa Kelas 1 SD Negeri Jubelan 02 Kecamatan Sumowono cenderung memiliki kriteria sedang $(4,17 \%)$ tetapi kategori kejadian karies anaknya cenderung tinggi $(54,17 \%)$. Hasil ini menunjukkan bahwa ibu mempunyai cukup bekal pengetahuan dan penanganan pada saat anak menyikat gigi, yaitu dalam hal ini seperti mendampingi dan menyikat gigi anak, tetapi pengetahuan teknik yang benar dari menyikat gigi sepertinya diabaikan oleh ibu. Termasuk cara pemilihan sikat gigi yang kurang sesuai dengan besar kecil rongga mulut anak. Pemilihan sikat gigi pada anak sebaiknya dipilih sikat gigi yang ukurannya kecil dengan tangkai yang mudah digenggam, bulu sikatnya halus, 
bagian kepala sikat menyempit agar mudah menjangkau bagian dalam rongga mulut (Gultom, 2011). Selain itu juga angka kejadian karies juga didapat dari faktor diluar peran seorang ibu, yaitu pola makan. Dimana anak kurang diawasi akan pola jajan ketika di sekolah, saat di sekolah anak menyenangi makan-makanan ringan seperti snack, biscuit di antara jam makan utama tanpa menyikat gigi atau berkumur-kumur setelahnya. Menurut Wong (2009) hal yang penting untuk diingat adalah seberapa sering anak mengkonsumsi makanan yang manis bukan jumlah makanan manis yang dimakan sekaligus. Setelah makan-makanan yang mengandung sukrosa $\mathrm{pH}$ mulut menurun dalam waktu 2,5 menit dan tetap rendah sampai selama 1 jam. Ini berarti jika gula pasir dikonsumsi 3 kali sehari $\mathrm{pH}$ mulut selama 3 jam akan berada di bawah 5,5. Proses demineralisasi yang terjadi selama periode waktu ini sudah cukup untuk mengikis lapisan email (Dumasari, 2010).

Berdasarkan tingkat pekerjaan, menunjukkan bahwa sebagian besar responden merupakan pekerja pabrik sebesar $41,67 \%$ yang berangkat pagi dan pulang menjelang sore hari. Peran pendidikan dalam hal ini pihak sekolah juga berperan pada upaya dalam pemeliharaan kesehatan gigi dan mulut siswanya. Berdasarkan hasil wawancara terhadap guru wali kelas diketahui bahwa sekolah tidak pernah memberikan pendidikan khusus tentang kesehatan gigi dan mulut, jikalau pernah pun hanya sekilas. Sehingga dimungkinkan anak tidak pernah mendapatkan pengetahuan cara penyikat gigi dan pengetahuan tentang pola makan yang benar. Menurut Besford (1992) dalam Rahayu (2010) bahwa untuk menyikat gigi secara benar diperlukan waktu lebih dari 2 menit atau bisa 5 menit untuk mendapatkan kesehatan gigi dan mulut yang optimal

\section{DAFTAR PUSTAKA}

Afilina G, Gracinis J, 2006, 75 Masalah Gigi Anak dan Solusinya, Elex Media Komputindo, Jakarta

Budiharto, 2010, Pengantar Ilmu Perilaku Kesehatan dan Pendidikan Kesehatan Gigi, EGC, Jakarta

Budiharto, 2008, Metodologi Penelitian Kesehatan, EGC, Jakarta

Depkes RI, 2008, Riset Kesehatan Dasar (RISKESDAS) 2007, Depkes RI, Jakarta

Hasanah, Nur, 2012, Studi Deskriptif Perilaku Kontrol Gigi Orang Tua Terhadap Anak Pada Kejadian Karies Gigi Anak Usia Sekolah Di SDN Purwosari 1 Semarang Utara, Universitas Muhammadiyah, Semarang

Herwanda, Bahar A, 2009, The Impact Of Oral Health Problem On School Children, KKPIKG, Jakarta

Kurnia, Ernita, 2010, Pengaruh Pendidikan Kesehatan Gosok Gigi Dengan Metode Permainan Simulasi Ular Tangga Terhadap Perubahan Pengetahuan, Sikap dan Aplikasi Tindakan Gosok Gigi Anak Usia Sekolah Di SD Wilayah Paron Ngawi,

http://isjd.pdii.lipi.go.id/admin/jur nal/131108391.pdf. (Akses tanggal 19 Juni 2014. Jam 08.00 WIB).

Kusumawati Dwi H, 2009, Hubungan Perilaku Ibu Tentang Kesehatan Gigi Anak Terhadap Angka Karies Pada Murid Kelas A TK Marsudisiswi 02, Poltekkes Semarang, Semarang

Machfoedz I, 2008, Memelihara Kesehatan Gigi dan Mulut Anak-anak dan Ibu Hamil, Fitramaya, Yogyakarta 
Notoadmojo S, 2012. Metodologi Penelitian Kesehatan, PT Rineka Cipta, Jakarta

Nurafifah, Dian, 2011, Hubungan Perilaku Pencegahan Karies Gigi Dan Kejadian Karies Gigi Pada Anak Di Dusun Sumberpanggang Desa Lopang Kecamatan Kemanghabu Kabupaten Lamongan, http://ejournal.ui.ac.id/sju/index.p hp/ujph/article/viewFile/185/187, 18 Juli 2014

Putri, MH, Eliza H, Neneng N, 2010, Ilmu Pencegahan Penyakit Jaringan Keras Gigi dan Jaringan Pendukung Gigi, EGC, Jakarta

Rahayu, Sri, 2010, Pengaruh Peran Orang Tua Terhadap Status Kebersihan Gigi dan Mulut (OHI-S) Pada Anak Di RT 05 Perum UNS $V$ Ngringo Kecamatan Jaten Kabupaten Karanganyar Tahun 2010, Poltekkes Semarang, Semarang

Sariningsih, Endang. 2012. Merawat Gigi Anak Sejak Usia Dini. Elex Media Komputindo, Jakarta

Sinaga, Anna, 2010. Faktor-Faktor Yang Berhubungan Dengan Perilaku Ibu Dalam Mencegah Karies Gigi Anak Usia 1-5 Tahun Di Puskesmas Babakan Sari Bandung,http://journal.unpad.ac.id/ sju/index.php/ujph/article/viewFil e/179/187, 5 Januari 2014

Tarigan, R, 2013, Karies Gigi, EGC, Jakarta

Widyastuti, Tri, 2010. Kejadian Karies Aktif Pada Anak Usia 3-5 Tahun Yang Tercatat Di Posyandu Wilayah Kerja Puskesmas Mohammad Ramdan Kota Bandung Tahun 2010 dan Faktor-Faktor Yang Memepengaruhinya, http://ejournal.ui.ac.id/sju/index.p hp/ujph/article/viewFile/185/187, 20 April 2014
Wong Donna. 2009. Buku Ajar Keperawatan Pediatri Vol 1. EGC, Jakarta 